\title{
CRESCIMENTO E ANATOMIA FOLIAR DE BANANEIRAS SUBMETIDAS A DIFERENTES CONDIÇÕES DE CULTIVO IN VITRO $\left({ }^{1}\right)$
}

\author{
FREDERICO HENRIQUE DA SILVA COSTA $\left({ }^{2 *}\right)$; MOACIR PASQUAL $\left({ }^{3,7}\right)$; HERMÍNIO SOUZA ROCHA $\left({ }^{4}\right)$; \\ JONNY EVERSON SCHERWINSKI PEREIRA $\left({ }^{5,7}\right)$; EVARISTO MAURO DE CASTRO $\left({ }^{3}\right)$; \\ LUZIA YURIKO MIYATA $\left({ }^{6}\right)$
}

\begin{abstract}
RESUMO
A realização de pesquisas que possibilitem redução dos custos de produção e ou melhoria na qualidade das mudas micropropagadas tem sido imprescindível para possibilitar a utilização e difusão deste tipo de material propagativo. O objetivo deste trabalho foi avaliar a influência de alterações no ambiente de cultivo sobre o crescimento e anatomia de bananeiras na fase de alongamento/enraizamento in vitro. Para tanto, brotações axilares das cultivares Caipira e Pacovan foram cultivadas em meio MS contendo ANA $\left(1 \mathrm{mg} \mathrm{L}^{-1}\right)$ e agar $\left(6 \mathrm{~g} \mathrm{~L}^{-1}\right)$, onde foram aplicados os tratamentos. Os tratamentos consistiram de concentrações de sacarose $\left(15 \mathrm{~g} \mathrm{~L}^{-1} \mathrm{e} 30 \mathrm{~g} \mathrm{~L}^{-1}\right)$ e ambientes de cultivo (Natural - casa de vegetação e Artificial - sala de crescimento). No fim de 45 dias, foram determinadas características de crescimento e de anatomia foliar. Houve influência significativa das alterações no ambiente de cultivo in vitro sobre as características avaliadas. Verificou-se que o uso da luz natural associada a $15 \mathrm{~g} \mathrm{~L}^{-1}$ de sacarose para a cultivar Caipira e $30 \mathrm{~g} \mathrm{~L}^{-1}$ para a Pacovan pode ser utilizada satisfatoriamente na fase de alongamento/enraizamento in vitro. Maior espessamento dos parênquimas clorofilianos e incremento na densidade estomática são induzidos em ambiente natural. A luz natural como alternativa às lâmapadas fluorescentes, no alongamento/enraizamento in vitro, representa potencial para reduzir os custos de produção e promover melhorias na anatomia foliar das mudas micropropagadas.
\end{abstract}

Palavras-chave: Musa spp., luz natural, enraizamento in vitro, sacarose.

\section{ABSTRACT \\ GROWTH AND LEAF ANATOMY OF BANANAS SUBMITTED TO DIFFERENT CONDITIONS OF IN VITRO CULTURE}

Initiatives aiming at to reduce production costs and to improve the quality of plantlets are necessary in order to turn micropropagation commercially more feasible. The objective of this work was to evaluate the influence of the environment on the growth and leaf anatomy of banana plantlets during in vitro elongating/ rooting phase. Shoots of Caipira and Pacovan cultivars were cultivated in MS medium, supplemented with NAA $\left(1 \mathrm{mg} \mathrm{L}^{-1}\right)$ and agar $\left(6 \mathrm{~g} \mathrm{~L}^{-1}\right)$, submitted to sucrose concentrations of $15 \mathrm{~g} \mathrm{~L}^{-1}$ or $30 \mathrm{~g} \mathrm{~L}^{-1}$ under natural light of greenhouse or artificial light of growth chamber. Investigations on growth and leaf anatomy were carried out after 45 days. It was observed that natural light and $15 \mathrm{~g} \mathrm{~L}^{-1}$ sucrose for 'Caipira' or $30 \mathrm{~g} \mathrm{~L}^{-1}$ for Pacovan cultivars promote thicker of chlorophyllian parenchyma and increased stomatal density. Natural light as an alternative to fluorescent bulbs during the in vitro elongating/rooting phase reduces the production costs and improve anatomical charachteristics of leaves of micropropagated banana plants.

Key words: Musa spp., natural light, in vitro rooting, sucrose.

(1) Recebido para publicação em 31 de julho de 2007 e aceito em 16 de outubro de 2008.

$\left({ }^{2}\right)$ Programa de Pós-Graduação em Fiototecnia, Universidade Federal de Lavras - UFLA, Caixa Postal 37, 37200-000 Lavras (MG).E-mail: fredericohenrique@yahoo.com.br ${ }^{*}$ ) Autor correspondente. Bolsista do CNPq.

$\left.{ }^{3}\right)$ Departamento de Agricultura, Universidade Federal de Lavras, Lavras (MG).

$\left({ }^{4}\right)$ Doutorando em Fitopatologia, UFLA, Lavras (MG).

$\left({ }^{5}\right)$ Embrapa Recursos Genéticos e Vegetais, Caixa Postal 02372, 70770-000 Brasília (DF).

$\left({ }^{6}\right)$ Graduando em Agronomia, UFLA (MG).

$\left({ }^{7}\right)$ Bolsista de Produtividade em Pesquisa do CNPq. 


\section{INTRODUÇÃO}

A banana tem destacada expressão econômica e social em todo o mundo, sendo considerada importante fonte de alimento e uma das frutas de maior consumo e produção entre as fruteiras tropicais (DonAto et al., 2006). No Brasil, segundo maior produtor mundial, a bananeira é cultivada de Norte a Sul do País, ocupando cerca de 490 mil hectares plantados (Borges et al., 2006). Um dos principais aspectos que limitam a expansão desta cultura é a utilização de mudas provenientes de métodos convencionais de propagação, que além da baixa taxa de multiplicação ( 3 a 8 filhotes por matriz/ciclo) (Vuylsteke e De Langhe, 1985), pode possibilitar a disseminação de pragas (RoELs et al., 2005).

Desta forma, a produção de mudas de bananeira utilizando a micropropagação de ápices caulinares, constitui-se importante ferramenta para a obtenção clonal massal de genótipos-elite (KozAI et al., 1997), proporcionando a rápida propagação e validação de variedades recentemente lançadas pelos programas de melhoramento genético da cultura (Gübbüк e Peкmezci, 2004; RochA, 2005). Relatos das primeiras aplicações da micropropagação na multiplicação de espécies do gênero Musa datam da década de 1960, havendo desde então, intensificação nos trabalhos de pesquisa visando à utilização de técnicas mais eficientes, produtivas e menos onerosas.

Dentre os avanços obtidos para diminuição dos custos de produção na micropropagação, a substituição das lâmpadas fluorescentes comumente utilizadas nas salas de crescimento pela luz natural, associado ou não a redução nos níveis exógenos de sacarose, são um dos mais importantes (Kodym e Zapata-Arias, 1999, 2001; SENDin, 2001; Rocha, 2005). Isso porque os gastos com iluminação artificial nas salas de cultivo chegam a representar $65 \%$ do total de energia elétrica utilizada nos laboratórios de cultura de tecidos de plantas (STANDAERT DE MetsenAere, 1991).

Efeitos benéficos da utilização da luz solar, associado a modificações na composição nutricional e física dos meios de cultura foram observados para as cultivares de bananeira Grande Naine (AAA) e Maçã (AAB), com redução nos custos de produção das mudas de até 90\% (Kodym e ZAPATA-Arias, 1999, 2001; SEndin, 2001). Contudo, a existência de informações e de entendimento sobre os efeitos advindos das modificações no ambiente de cultivo in vitro, especialmente pelo uso da luz natural, sobre as plantas cultivadas in vitro ainda são incipientes.

Objetivou-se com este trabalho, avaliar a influência de alterações no ambiente de cultivo sobre o crescimento e a anatomia de bananeiras na fase de alongamento/enraizamento in vitro.

\section{MATERIAL E MÉTODOS}

O trabalho foi desenvolvido no município de Lavras (MG), Brasil a $21^{\circ} 14^{\prime} \mathrm{S}, 45^{\circ} 17^{\prime} \mathrm{W}$ e $918 \mathrm{~m}$ de altitude, entre março e maio de 2006. Segundo KöPPEN (1948), a região possui duas estações definidas: seca com temperaturas mais baixas, de abril a setembro, e chuvosa com temperaturas mais elevadas, de outubro a março.

Como material vegetal, utilizaram-se brotações axilares ( 2 a $3 \mathrm{~cm}$ e 1 a 2 folhas expandidas), obtidas do estabelecimento e multiplicação in vitro de ápices caulinares de plantas matrizes das cultivares Caipira (AAA) e Pacovan (AAB). Para a obtenção das brotações foi utilizado o meio MS (MURASHIGE e SKOOG, 1962), contendo $5 \mathrm{mg} \mathrm{L}^{-1}$ de BAP (6benzilaminopurina). Os subcultivos, realizados a cada 35 dias, foram mantidos em sala de crescimento a 25 ${ }^{\circ} \mathrm{C} \pm 2{ }^{\circ} \mathrm{C}$ e 16 horas de irradiância de $35 \mu \mathrm{mol} \mathrm{m} \mathrm{m}^{-2} \mathrm{~s}^{-1}$.

Obtidos os explantes, estes foram submetidos à fase de alongamento/enraizamento in vitro em meio constituído pelos sais e vitaminas de MS, suplementado com $1 \mathrm{mg} \mathrm{L}^{-1}$ de ANA (ácido naftalenoacético), por 45 dias. Todos os meios utilizados foram solidificados com $6 \mathrm{~g} \mathrm{~L}^{-1}$ de ágar $\left(\right.$ Merse $^{\circledR}$ ) e tiveram o pH ajustado para 5,8 $\pm 0,1$ antes da adição do agente geleificante. Os tratamentos, dispostos em esquema fatorial $2 \times 2$, consistiram de concentrações de sacarose $\left(15 \mathrm{~g} \mathrm{~L}^{-1}\right.$ e $\left.30 \mathrm{~g} \mathrm{~L}^{-1}\right)$ e ambientes de cultivo (Sala de crescimento - ambiente artificial e Casa de vegetação - ambiente natural), avaliados para as cultivares Caipira e Pacovan. Cada tratamento foi representado por cinco repetições e quatro explantes por parcela (frasco). O cultivo foi feito em frascos de $250 \mathrm{~mL}$ contendo $40 \mathrm{~mL}$ de meio, selados com filme plástico transparente.

$\mathrm{O}$ ambiente artificial constituiu-se de uma sala de crescimento, com iluminação fornecida por lâmpadas fluorescentes tubulares do tipo luz do dia especial (Osram 20 W) (16 horas de irradiância a 35 $\mu \mathrm{mol} \mathrm{m} \mathrm{m}^{-2} \mathrm{~s}^{-1}$ ) e temperatura de $25{ }^{\circ} \mathrm{C} \pm 2{ }^{\circ} \mathrm{C}$. Já o ambiente natural consistiu de uma casa de vegetação, coberta com filme de polietileno transparente com tratamento contra raios ultravioleta (150 microns) e sombreamento de $70 \%$ (Sombrence ${ }^{\circledR}$ ), possuindo os seguintes parâmetros ambientais: temperaturas máximas, mínimas e médias de $26{ }^{\circ} \mathrm{C} / 32{ }^{\circ} \mathrm{C} ; 16{ }^{\circ} \mathrm{C} /$ $16^{\circ} \mathrm{C}$ e $20^{\circ} \mathrm{C} / 23^{\circ} \mathrm{C}$ e níveis de irradiância máximos, mínimos e médios de 432,17 $\mu \mathrm{mol} \mathrm{m}^{-2} \mathrm{~s}^{-1} / 918,57 \mu \mathrm{mol}$ $\mathrm{m}^{-2} \mathrm{~s}^{-1} ; 51,20 \mu \mathrm{mol} \mathrm{m}^{-2} \mathrm{~s}^{-1} / 49,04 \mu \mathrm{mol} \mathrm{m}^{-2} \mathrm{~s}^{-1}$ e 227,15 $4 \mathrm{~mol} \mathrm{~m} \mathrm{~m}^{-2} \mathrm{~s}^{-1} / 457,38 \mu \mathrm{mol} \mathrm{m} \mathrm{m}^{-2} \mathrm{~s}^{-1}$, respectivamente, 
referentes a dias nublados e claros típicos do período de experimentação. Dados referentes à radiação solar diurna, incidente na altura dos frascos, foram mensurados por sensores de radiação (LI-200SA, Licor, Lincoln, Nebrasca, USA), acoplados a um sistema de registro (LI 1400; Li-cor.Neb), com as leituras realizadas a cada meia hora durante 11 horas (das 7 às 18 horas). Para o ambiente artificial, a irradiância foi medida apenas durante 6 horas, visto se tratar de ambiente controlado. Os dados referentes às médias semanais de temperatura foram obtidos com termohigrógrafo.

Decorrido o enraizamento in vitro, os seguintes parâmetros foram avaliados: altura da parte aérea, número de folhas senescentes e massa seca total, este último obtido após secagem a $60^{\circ} \mathrm{C}$ por 48 horas. Em adição, foram desenvolvidas observações anatômicas em seções transversais e paradérmicas (das faces adaxial e abaxial da epiderme), obtidas em micrótomo de mesa manual e à mão livre, com auxílio de lâmina de barbear (Gillette ${ }^{\circledR}$ ). Para a obtenção dos cortes, foi utilizado o terço médio da segunda folha expandida (em direção ápice-base), previamente fixada em FAA 70 (formaldeído, ácido acético e álcool etílico) (JoHANSEN, 1940) por 72 horas e conservada em álcool etílico $70 \%$ (v/v). A preparação das seções foi feita por clarificação em hipoclorito de sódio $(1,0-$ $1,25 \%$ de cloro ativo), seguido de tríplice lavagem em água destilada, coloração com azul de astra-safranina e safranina $1 \%$ (transversais e paradérmicas respectivamente) (KRAUS e ARDUIN, 1997) e montagem em água glicerinada.

Com auxílio de microscópio Ken-a-vision 2100, ocular micrométrica e objetiva de 40X, foram avaliadas as espessuras dos parênquimas paliçádico e esponjoso e das hipodermes abaxial e adaxial, efetuando-se duas medições em cinco folhas/ tratamento, na região após o terceiro feixe lateral, totalizando 10 medições/tratamento. Em adição, a espessura do limbo foliar foi mensurada. Para os cortes paradérmicos, apenas a densidade estomática foi avaliada, sendo expressa em número de estômatos por $\mathrm{mm}^{2}$, segundo a técnica de LABOURIAU et al. (1961). Para esta análise, as avaliações ocorreram em quatro campos no terço mediano de seis folhas/tratamento, perfazendo-se um total de 24 campos por tratamento. Para isso, um microscópio de luz (Olympus CBB), uma câmara clara (com campos de $0,065 \mathrm{~mm}^{2}$ ) e uma objetiva de 40X foram utilizados.

O delineamento experimental foi o inteiramente casualizado. Os dados foram inicialmente submetidos às análises de variâncias individuais (para cada ambiente de cultivo), realizando em seguida o teste de homogeneidade de variância e a análise conjunta dos ambientes. Para isso, o programa estatístico Sisvar 4.3 (FERREIRA, 2000) foi utilizado, sendo as médias comparadas pelo Teste F a $5 \%$ de probabilidade.

\section{RESULTADOS E DISCUSSÃO}

\section{Características fitotécnicas}

Interação significativa entre os fatores estudados (Ambiente x Sacarose) foi observada apenas para o número de folhas senescentes, tanto na cultivar Caipira quanto na 'Pacovan'. Em relação às demais variáveis, o efeito isolado dos fatores foi verificado variando em função da cultivar utilizada (Tabela 1).

Para a altura da parte aérea, maior média foi obtida sob ambiente artificial nas duas cultivares utilizadas $(p \leq 0,05)$. Entre as concentrações de sacarose, diferença significativa ocorreu apenas para a cultivar Pacovam, cuja maior altura da parte aérea ocorreu com $15 \mathrm{~g} \mathrm{~L}^{-1}$ de sacarose. Provavelmente, o principal fator responsável pelo reduzido crescimento das plantas sob luz natural tenha sido a ocorrência de baixas temperaturas $\left(16{ }^{\circ} \mathrm{C}\right.$ e $\left.20{ }^{\circ} \mathrm{C}\right)$ nesta condição de cultivo.

De acordo com Robinson (2003), a bananeira é uma espécie frutífera tropical, para a qual a temperatura ótima para emergência foliar é cerca de $31{ }^{\circ} \mathrm{C}$, e a ótima para o crescimento (assimilação) e o desenvolvimento é cerca de $27^{\circ} \mathrm{C}$. Resultados contrários para a altura da parte aérea foram observados por Rocha (2005) para a cv. Prata-Anã (AAB). Todavia, o trabalho de RochA (2005) foi desenvolvido em Cruz das Almas (BA), região com temperaturas médias mais elevadas em relação àquelas verificadas no presente estudo (Lavras, MG), justificando assim as possíveis diferenças.

Outra possível razão para a menor altura sob ambiente natural pode ser atribuída ao fato de as brotações utilizadas terem sido oriundas de um ambiente (sala de crescimento) com nível de irradiância inferior àqueles verificados durante o período de cultivo sob ambiente natural. Desta maneira, a transferência destas brotações para a luz natural pode ter causado maior estresse nos dias iniciais da exposição ao tratamento de casa de vegetação, diferentemente do tratamento artificial, no qual as brotações continuaram sob o mesmo nível de irradiância, favorecendo assim seu crescimento. 
Tabela 1. Valores médios para altura da parte aérea, número de folhas senescentes e matéria seca total de plantas de bananeira, cvs. Caipira e Pacovan, sob a influência do ambiente de cultivo e concentração de sacarose, após 45 dias de enraizamento in vitro

\begin{tabular}{|c|c|c|c|c|c|c|}
\hline \multirow{2}{*}{ Ambiente } & \multicolumn{2}{|c|}{ Caipira } & \multirow{2}{*}{ Média } & \multicolumn{2}{|c|}{ Pacovan } & \multirow{2}{*}{ Média } \\
\hline & 15 & 30 & & 15 & 30 & \\
\hline
\end{tabular}

\begin{tabular}{|c|c|c|c|c|c|c|}
\hline \multirow[b]{2}{*}{ Natural } & \multicolumn{5}{|c|}{ Altura da parte aérea $(\mathrm{cm})$} & \multirow[b]{2}{*}{$3,72 b$} \\
\hline & 4,13 & 4,35 & $4,24 \mathrm{~b}$ & 4,09 & 3,35 & \\
\hline Artificial & 6,48 & 6,62 & $6,55 \mathrm{a}$ & 7,48 & 6,14 & $6,81 \mathrm{a}$ \\
\hline Média & $5,30 \mathrm{~A}$ & $5,49 \mathrm{~A}$ & - & $5,79 \mathrm{~A}$ & $4,75 \mathrm{~B}$ & - \\
\hline CV (\%) & - & 8,3 & - & - & 10,58 & - \\
\hline
\end{tabular}

\begin{tabular}{|c|c|c|c|c|c|c|}
\hline \multirow[b]{2}{*}{ Natural } & \multicolumn{6}{|c|}{ Folnas senescentes (n. ) } \\
\hline & $2,00 \mathrm{aA}$ & $1,17 \mathrm{aB}$ & $1,58 \mathrm{a}$ & 1,85 aA & 1,60 aA & $1,73 \mathrm{a}$ \\
\hline Artificial & $0,40 \mathrm{bA}$ & $0,15 \mathrm{bA}$ & $0,27 \mathrm{~b}$ & $0,45 \mathrm{bB}$ & $0,98 \mathrm{bA}$ & $0,72 \mathrm{~b}$ \\
\hline Média & $1,20 \mathrm{~A}$ & $0,66 \mathrm{~B}$ & - & $1,15 \mathrm{~A}$ & $1,29 \mathrm{~A}$ & - \\
\hline \multirow[t]{2}{*}{ CV (\%) } & - & 24,31 & - & - & 32,34 & - \\
\hline & \multicolumn{6}{|c|}{ Matéria seca total (g) } \\
\hline Natural & 0,11 & 0,10 & 0,11 a & 0,10 & 0,13 & $0,12 \mathrm{~b}$ \\
\hline Artificial & 0,10 & 0,11 & 0,10 a & 0,12 & 0,18 & $0,15 \mathrm{a}$ \\
\hline Média & $0,10 \mathrm{~A}$ & $0,11 \mathrm{~A}$ & - & $0,11 \mathrm{~B}$ & $0,16 \mathrm{~A}$ & - \\
\hline CV (\%) & - & 28,20 & - & - & 15,05 & - \\
\hline
\end{tabular}

Médias seguidas por letras distintas, minúscula na vertical e maiúscula na horizontal, dentro de cada variável, diferem entre si pelo teste de F a $5 \%$ de probabilidade.

Quanto ao número de folhas senescentes, o cultivo sob luz natural promoveu maior senescência das folhas $(p \leq 0,05)$, em ambas as cultivares estudadas. Para as concentrações de sacarose, efeito significativo foi verificado somente na 'Caipira' com maior número de folhas senescentes para $15 \mathrm{~g} \mathrm{~L}^{-1}$ de sacarose. Estudando a interação, maior número de folhas senescentes também ocorreu sob ambiente natural, em ambas as concentrações de sacarose e para as duas cultivares avaliadas (Tabela 2). Resultados semelhantes para a senescência foliar em decorrência do incremento da irradiância (PPFDs, densidade de fluxo fótons fotossintéticos) são reportados por JoRGE et al. (2000) em plantas de mandioca (Manihot esculenta).

No presente estudo, a maior senescência sob luz natural se deve provavelmente ao fato de os explantes utilizados serem oriundos de um nível de irradiância menor e uniforme em relação aos verificados para a luz natural. Observou-se que tanto nas folhas já expandidas quanto naquelas em formato de cartucho (folha denominada zero) formadas sob condição de luz artificial, quando transferidas ao ambiente de luz natural, em sua maioria, houve estresse fotoxidativo com queima do limbo foliar e senescência no pseudocaule, ocorrendo a emissão de novas folhas sob luz natural. É importante mencionar, ainda, que as brotações utilizadas possuíam entre 1 a 2 folhas expandidas, concordando com a média de senescência verificada sob luz natural, 1,58 e 1,73 para as cultivares Caipira e Pavocan.

A senescência das folhas formadas sob luz artificial nas plantas enraizadas em ambiente natural pode trazer benefícios às plantas no sentido de que, todas as novas folhas seriam mais adaptadas às variações ambientais no momento do transplantio $e x$ vitro (aclimatização). Isso porque o ambiente de luz natural proporciona condições ambientais tanto de temperatura quanto de irradiância mais parecidas ao ambiente ex vitro, minimizando o grau de estresse e a perda de plantas na aclimatização. Além disso, conforme os resultados da anatomia (Tabela 2), nas folhas provenientes do enraizamento em luz natural há maior desenvolvimento (espessura) dos parênquimas clorofilianos. De acordo com ARAGON et al. (2006), as diferenças ambientais entre as condições in vitro e ex vitro, especialmente quanto à intensidade luminosa e umidade relativa, podem ocasionar elevada transpiração e morte das plantas no momento da aclimatização. Ainda a respeito do ambiente de cultivo in vitro Fuentes et al. (2007) afirmam ser possível melhorar a fisiologia e o subsequente comportamento ex vitro de plantas micropropagadas. Segundo estes autores, a manipulação de alguns 
fatores abióticos in vitro como, por exemplo, o aumento na intensidade e qualidade da luz é promissor particularmente para plantas tropicais, citando inclusive o uso da luz natural nos últimos estágios do processo de micropropagação.

Sob as mesmas condições do presente experimento, SANTOS et al. (2007) verificaram que plantas de bananeira cv. Caipira, quando enraizadas sob iluminação natural retêm maior conteúdo relativo de água após sua remoção dos frascos de cultivo e, consequentemente, são menos propensas à perda de água durante os dias iniciais do transplantio ex vitro. Por outro lado, os autores afirmam que plantas enraizadas sob luz artificial possuem maior murcha das folhas após 12 horas de exposição às condições de laboratório (aproximadamente $63 \%$ de umidade relativa e temperatura de $25 \pm 2{ }^{\circ} \mathrm{C}$ ).

Tabela 2. Valores médios para espessura de parênquimas, hipodermes e limbo foliar de plantas de bananeira, cvs. Caipira e Pacovan, sob a influência do ambiente de cultivo e concentração de sacarose, após 45 dias de enraizamento in vitro

\begin{tabular}{|c|c|c|c|c|c|c|}
\hline \multirow{2}{*}{ Ambiente } & \multicolumn{2}{|c|}{ Caipira } & \multirow{2}{*}{ Média } & \multicolumn{2}{|c|}{ Pacovan } & \multirow{2}{*}{ Média } \\
\hline & 15 & 30 & & 15 & 30 & \\
\hline & \multicolumn{2}{|c|}{$\mathrm{g} \mathrm{L}^{-1}-$} & & \multicolumn{2}{|c|}{$\longrightarrow \mathrm{g} \mathrm{L}^{-1}$} & \\
\hline & \multicolumn{5}{|c|}{ Parênquima paliçádico $(\mu \mathrm{m})$} & \\
\hline Natural & 67,95 & 66,60 & $67,28 \mathrm{a}$ & $71,55 \mathrm{aB}$ & 82,80 aA & 77,18 a \\
\hline Artificial & 48,15 & 54,10 & $51,13 \mathrm{~b}$ & $51,75 \mathrm{bA}$ & $42,30 \mathrm{bB}$ & $47,03 \mathrm{~b}$ \\
\hline Média & $58,05 \mathrm{~A}$ & $60,35 \mathrm{~A}$ & - & $61,65 \mathrm{~A}$ & $62,55 \mathrm{~A}$ & - \\
\hline \multirow[t]{2}{*}{ CV $(\%)$} & - & 13,11 & - & - & 10,40 & - \\
\hline & \multicolumn{5}{|c|}{ Parênquima esponjoso $(\mu \mathrm{m})$} & \\
\hline Natural & 85,50 & 79,20 & 82,35 a & $62,55 \mathrm{aB}$ & $76,95 \mathrm{aA}$ & 69,75 a \\
\hline Artificial & 67,95 & 66,00 & $66,98 \mathrm{~b}$ & 61,5 aA & $42,75 \mathrm{bB}$ & $52,20 \mathrm{~b}$ \\
\hline Média & $76,73 \mathrm{~A}$ & $72,60 \mathrm{~A}$ & - & $62,10 \mathrm{~A}$ & $59,85 \mathrm{~A}$ & - \\
\hline \multirow[t]{2}{*}{ CV $(\%)$} & - & 15,50 & - & - & 14,26 & - \\
\hline & \multicolumn{5}{|c|}{ Hipoderme abaxial $(\mu \mathrm{m})$} & \\
\hline Natural & 47,25 & 45,90 & $46,58 \mathrm{~b}$ & 43,20 & 44,10 & $43,65 \mathrm{a}$ \\
\hline Artificial & 48,15 & 52,20 & 50,18 a & 41,40 & 42,75 & 42,08 a \\
\hline Média & $47,70 \mathrm{~A}$ & $49,05 \mathrm{~A}$ & - & $42,30 \mathrm{~A}$ & $43,43 \mathrm{~A}$ & - \\
\hline \multirow[t]{2}{*}{ CV $(\%)$} & - & 11,24 & - & - & 13,34 & - \\
\hline & \multicolumn{5}{|c|}{ Hipoderme adaxial $(\mu \mathrm{m})$} & \\
\hline Natural & $44,10 \mathrm{bA}$ & $49,50 \mathrm{bA}$ & $46,80 \mathrm{~b}$ & $52,20 \mathrm{bA}$ & 56,25 aA & $54,23 \mathrm{~b}$ \\
\hline Artificial & 79,65 aA & $59,70 \mathrm{aB}$ & $69,68 \mathrm{a}$ & $71,55 \mathrm{aA}$ & $53,55 \mathrm{aB}$ & $62,55 \mathrm{a}$ \\
\hline Média & $61,88 \mathrm{~A}$ & $54,60 \mathrm{~B}$ & - & $61,88 \mathrm{~A}$ & $54,90 \mathrm{~A}$ & - \\
\hline \multirow[t]{2}{*}{ CV (\%) } & - & 11,97 & - & - & 18,82 & - \\
\hline & \multicolumn{5}{|c|}{ Limbo foliar $(\mu \mathrm{m})$} & \\
\hline Natural & 277,20 & 268,20 & $272,70 \mathrm{a}$ & $256,95 \mathrm{aB}$ & 287,10 aA & 272,03 a \\
\hline Artificial & 279,90 & 264,85 & 272,38 a & 255,15 aA & $208,35 \mathrm{bB}$ & $231,75 \mathrm{~b}$ \\
\hline Média & $278,55 \mathrm{~A}$ & 266,53 B & - & $256,05 \mathrm{~A}$ & 247,73 A & - \\
\hline CV (\%) & - & 6,45 & - & - & 6,97 & - \\
\hline
\end{tabular}

Médias seguidas por letras distintas, minúsculas na vertical e maiúsculas na horizontal, dentro de cada variável, diferem entre si pelo teste de $\mathrm{F}$ a $5 \%$ de probabilidade. 
Em relação à matéria seca total, nenhum efeito significativo dos fatores em estudo (Ambiente e Sacarose), isolado ou associados, foi observado para a cultivar Caipira. Ao contrário, na cv. Pacovan notou-se maior quantidade de matéria seca para o ambiente artificial e na concentração de $30 \mathrm{~g} \mathrm{~L}^{-1}$ de sacarose $(p \leq 0,05)$ (Tabela 2). Maiores valores para a matéria seca em plantas cultivadas em meio de enraizamento contendo $30 \mathrm{~g} \mathrm{~L}^{-1}$ de sacarose e sob luz natural ou artificial é reportado por RochA (2005) em bananeira 'Prata-Anã'. De acordo com Fuentes et al. (2007), o descréscimo na concentração de sacarose do meio de cultivo pode até melhorar a fotossíntese das plantas, mas pode afetar o crescimento das plantas sob a condição padrão de baixa irradiância frequentemente usada nas salas de crescimento. Para esses autores, uma alternativa seria reduzir a concentração de sacarose e aumentar pelo menos 10 vezes a intensidade luminosa das salas de crescimento em alguns sistemas de micropropagação.

Quanto ao aumento nos níveis de irradiância, Navarro et al. (1994), trabalhando com a cv. 'Grande Naine' (AAA), observaram que após 30 dias de cultivo in vitro, o rendimento de massa seca sob alta intensidade luminosa $\left(240 \mu \mathrm{mol} \mathrm{m}^{-2} \mathrm{~s}^{-1}\right)$ foi 2,3 vezes superior ao tratamento controle $\left(30 \mu \mathrm{mol} \mathrm{m} \mathrm{m}^{-2} \mathrm{~s}^{-1}\right)$. Nesse mesmo raciocínio, Marchal et al. (1992) afirmam que o aumento da intensidade luminosa de $45 \mu \mathrm{mol} \mathrm{m}{ }^{-2} \mathrm{~s}^{-1}$ para $340 \mu \mathrm{mol} \mathrm{m} \mathrm{s}^{-2}$, com $40 \mathrm{~g} \mathrm{~L}^{-1} \mathrm{de}$ sacarose, promove ganho de massa fresca $(1,89 \mathrm{~g}$ e $3,87 \mathrm{~g})$ e seca $(0,12 \mathrm{~g}$ e $0,24 \mathrm{~g})$ em plantas de bananeira cv. Grande Naine (AAA), além de causar redução quanto à altura da parte aérea $(3,33 \mathrm{~cm}$ e $2,88 \mathrm{~cm})$.

Efeitos benéficos do cultivo in vitro em condições de luz natural (estufa) foram também reportados por TALAVERA et al. (2005) em plantas de Cocos nucifera L. De acordo com estes autores, no fim da fase in vitro plantas crescendo em estufa ou sala de crescimento modificada (com luz natural) tiveram maior taxa fotossintética comparada às plantas cultivadas em sala de crescimento convencional. Os autores observaram ainda que, em termos de crescimento, as condições de estufa foram ligeiramente melhores quanto ao acúmulo de massa fresca e seca das plantas, assim como para número de folhas.

\section{Características anatômicas}

Efeito significativo da interação entre os fatores em estudo (Ambiente $x$ Sacarose) foi verificado. $\mathrm{Na}$ cultivar Caipira, a interação ocorreu apenas para a variável espessura da hipoderme adaxial e densidade estomática abaxial (Tabelas 2 e 3). Já para a 'Pacovan', as variáveis influenciadas pela interação foram: espessura dos parênquimas, da hipoderme adaxial e do limbo foliar (Tabela 2). Nas demais características avaliadas, os fatores influenciaram isoladamente, dependendo da cultivar.

Em relação aos parênquimas, tanto no paliçádico quanto no esponjoso, notou-se maior espessura sob ambiente natural em ambas as cultivares Caipira e Pacovan $(p \leq 0,05)$. Por outro lado, nenhuma diferença significativa entre as concentrações de sacarose foi observada. Avaliando a interação na cv. Pacovan, maior espessamento de parênquimas entre os ambientes de cultivo ocorreu para a luz natural, nas duas concentrações de sacarose estudadas $(p \leq 0,05)$ (Tabela 2$)$.

Efeito positivo do aumento da irradiância sobre o espessamento do parênquima paliçádico foi observado por HANBA et al. (2002) em espécies de Acer in vitro e Rocha (2005) em bananeira 'Prata-Anã'. Em adição, DecCetti (2004) afirma que em plantas de Annona glabra enraizadas in vitro sob $300 \mu \mathrm{mol} \mathrm{m}^{-2} \mathrm{~s}^{-1}$ verificaram-se aumentos significativos na espessura dos parênquimas paliçádico e esponjoso. Ainda segundo este autor, a pronunciada diferenciação dos parênquimas pode ser determinante na otimização do processo de fotossíntese e promover benefício na sobrevivência ex vitro das plantas. AmÂNCIO et al. (1999) atestam que o efeito da luz sobre o desenvolvimento do mesofilo, principalmente o parênquima paliçádico, é certamente o fator anatômico determinante para possíveis incrementos na atividade fotossintética.

Quanto à espessura das hipodermes, maior espessamento entre os ambientes de cultivo foi obtido para a luz artificial $(p \leq 0,05)$, exceto para a hipoderme abaxial na cultivar Pacovan. Entre as concentrações de sacarose, apenas na hipoderme adaxial houve diferença significativa, com maior espessamento com $15 \mathrm{~g} \mathrm{~L}^{-1}$ de sacarose. Analisando o efeito da interação para a hipoderme adaxial, maior espessura na cultivar Caipira ocorreu em ambiente artificial, nas duas concentrações de sacarose testadas. Para a 'Pacovan', apenas na concentração de $15 \mathrm{~g} \mathrm{~L}^{-1}$ o ambiente artificial promoveu maior espessura da hipoderme adaxial $(p \leq 0,05)$ (Tabela 2$)$.

No limbo foliar da cv. Caipira não houve diferença significativa entre os ambientes de cultivo testados, diferentemente da 'Pacovan', cuja espessura foi significativamente maior sob luz natural (Tabela 2). No entanto, entre as concentrações de sacarose, foi observada diferença significativa apenas para a cultivar Caipira, que teve maior espessamento quando cultivada com $15 \mathrm{~g} \mathrm{~L}^{-1}$ de sacarose. Maior espessura do limbo foliar em resposta ao aumento da irradiância em plantas crescendo in vitro também foi reportada por Hanba et al. (2002) em espécies de Acer. 
Tabela 3. Valores médios para densidade estomática (.$^{\circ}$ de estômatos por $\mathrm{mm}^{2}$ ) em folhas de plantas de bananeira, cv. Caipira e Pacovan, sob a influência do ambiente de cultivo e concentração de sacarose, após 45 dias de enraizamento in vitro

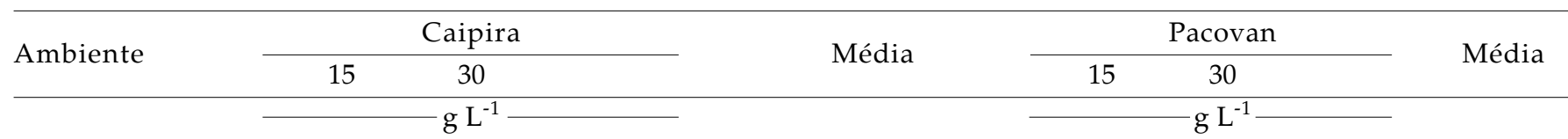

Densidade estomática abaxial (estômatos por $\mathrm{mm}^{2}$ )

\begin{tabular}{|c|c|c|c|c|c|c|}
\hline Natural & $158,08 \mathrm{aA}$ & $167,25 \mathrm{aA}$ & $162,67 \mathrm{a}$ & 149,33 & 147,58 & $148,46 \mathrm{a}$ \\
\hline Artificial & $150,75 \mathrm{aA}$ & $131,25 \mathrm{bB}$ & $141,00 \mathrm{~b}$ & 121,92 & 126,25 & $124,08 \mathrm{~b}$ \\
\hline Média & $154,42 \mathrm{~A}$ & $149,25 \mathrm{~A}$ & - & $135,63 \mathrm{~A}$ & $136,92 \mathrm{~A}$ & - \\
\hline \multirow[t]{2}{*}{ CV $(\%)$} & - & 12,42 & - & - & 14,86 & - \\
\hline & \multicolumn{6}{|c|}{ Densidade estomática adaxial (estômatos por $\mathrm{mm}^{2}$ ) } \\
\hline Natural & 34,83 & 36,08 & $35,46 \mathrm{a}$ & 52,00 & 56,92 & $54,46 \mathrm{a}$ \\
\hline Artificial & 29,25 & 32,92 & $31,08 \mathrm{a}$ & 45,33 & 42,17 & $43,75 \mathrm{~b}$ \\
\hline Média & $32,04 \mathrm{~A}$ & $34,50 \mathrm{~A}$ & - & $48,67 \mathrm{~A}$ & $49,54 \mathrm{~A}$ & - \\
\hline CV (\%) & - & 27,40 & - & - & 25,15 & - \\
\hline
\end{tabular}

Médias seguidas por letras distintas, minúscula na vertical e maiúscula na horizontal, dentro de cada variável, diferem entre si pelo teste de F a $5 \%$ de probabilidade.

Em relação à densidade estomática da epiderme abaxial, maior média entre os ambientes de cultivo foi verificada sob luz natural, tanto para a cv. Caipira quanto 'Pacovan' $(p \leq 0,05)$. Em ambas as cultivares estudadas, as concentrações de sacarose não diferiram significativamente entre si para esta variável. Além disso, analisando a cv. Caipira, diferença significativa entre os ambientes de cultivo foi observada apenas com $30 \mathrm{~g} \mathrm{~L}^{-1}$ de sacarose, onde maior número de estômatos por $\mathrm{mm}^{2}$ ocorreu sob ambiente natural (Tabela 3 ).

Para a densidade estomática da epiderme adaxial, diferença entre os ambientes de cultivo foi observada somente na cultivar Pacovan, com maior média sob luz natural $(p \leq 0,05)$. Quanto às concentrações de sacarose, estas não diferiram significativamente entre si, tanto na cultivar Caipira quanto na 'Pacovan' (Tabela 3).

Observações semelhantes para a densidade estomática foram obtidas por RochA (2005) para a cultivar 'Prata-Anã' (AAB) na fase de enraizamento, quando maior número de estômatos por $\mathrm{mm}^{2}$ da face abaxial ocorreu em ambiente artificial com $15 \mathrm{~g} \mathrm{~L}^{-1} \mathrm{e}$ natural com 15 ou $30 \mathrm{~g} \mathrm{~L}^{-1}$ de sacarose. De acordo com Lima JUNIOR et al. (2005), o aumento no número de estômatos por área, bem como no número de células e índice estomático em plantas de $C$. vernalis cultivadas são observados a pleno sol e $30 \%$ de sombreamento. Em experimento desenvolvido com Annona glabra, constatou-se que a maior irradiância promoveu o aumentou da densidade estomática na fase de enraizamento in vitro (DeCCETTI, 2004).
De modo geral, informações a respeito das contribuições da estrutura foliar para a fotossíntese e o crescimento das plantas (SмIтH et al. 1997) podem contribuir para melhor entendimento e permitir a elucidação de lacunas acerca das diferenças nas taxas de crescimento de plantas (LAmbers e PoOrter, 1992), além de fornecer subsídios sobre quais procedimentos realizar na etapa de retirada das plantas dos recipientes de cultivo, otimizando assim a aclimatização ex vitro. Adicionalmente, as alterações que ocorrem na estrutura interna das folhas induzidas por modificações nos níveis de irradiância, se constituem em aspectos determinantes na capacidade de aclimatização das espécies submetidas a condições ambientais distintas (HANBA et al., 2002).

\section{CONCLUSÕES}

1. Maior altura da parte área e espessura da hipoderme ocorrem em plantas de bananeira enraizadas sob ambiente artificial.

2. O alongamento/enraizamento in vitro de bananeiras sob luz natural promove espessamento dos parênquimas clorofilianos e aumento na densidade estomática.

3. O uso da luz natural associada a $15 \mathrm{~g} \mathrm{~L}^{-1}$ de sacarose para a cv. Caipira e $30 \mathrm{~g} \mathrm{~L}^{-1}$ para a cv. Pacovan pode ser utilizada satisfatoriamente na fase de alongamento/enraizamento in vitro. 
4. A luz natural, como alternativa ao uso de lâmapadas fluorescentes, na fase de alongamento/ enraizamento in vitro, possui potencial para reduzir os custos de produção de mudas de bananeira micropropagadas;

\section{AGRADECIMENTOS}

Ao Conselho Nacional de Desenvolvimento Científico e Tecnológico (CNPq), pelo apoio financeiro e bolsas concedidas.

\section{REFERÊNCIAS}

AMÂNCIO, S.; REBORDÃO, J.P.; CHAVES, M.M. Improvement of acclimatization of micropropagated grapevine: photosynthetic competence and carbon allocation. Plant Cell, Tissue and Organ Culture, Amsterdam, v. 58, n. 1, p. 31-37, 1999.

ARAGON, C.; ESCALONA, M.; CAPOTE, I.; PINA, D.;CEJAS, I.; RODRIGUEZ, R.; NOCEDA, C.; SANDOVAL, J.; ROELS, S.; DEBERGH, P.; GONZALEZ-OLMEDO, J.L. Metabolic importance of starch in the acclimation of plantain 'CEMSA 3/4' (AAB) plants. Infomusa, v.15, n.1-2, p.32-35, 2006.

BORGES, A.L.; SILVA, S. de O.; CALDAS, R.C.; LEDO, C.A. da $\mathrm{S}$. Teores foliares de nutrientes em genótipos de bananeira. Revista Brasileira de Fruticultura, Jaboticabal, v. 28, n. 2, p. 314-318, Agosto 2006.

DECCETTI, S.F.C. Ambiente de cultivo e respostas morfofisiológicas durante o processo de micropropagação de Annona glabra L. 2004. 93p. :il. Tese (Doutorado em Fisiologia Vegetal), Universidade Federal de Lavras, Lavras.

DONATO, S.L.R.; SILVA, S. de O.; FILHO, O.A.L.; LIMA, M.B.; DOMINGUES, H.; ALVES, J. da S. Comportamento de variedades e híbridos de bananeira (Musa spp.) em dois ciclos de produção no Sudoeste da Bahia. Revista Brasileira de Fruticultura, Jaboticabal, v. 28, n. 1, p. 139-144, Abril 2006.

FERREIRA, D.F. SISVAR 4.3: sistema de análise estatística. Lavras: UFLA;DEX, 2000. Software.

FUENTES, G.; TALAVERA, C.; ESPADAS, F.; QUIROZ, A.; AGUILAR, M.; COELHO, J.; SANTAMARIA, J.M. Manipulation of abiotic in vitro factors to improve the physiology and subsequent field performance of micropropagated plantlets. Acta Horticulturae, Wageningen, n.748, p.77-86, 2007.

GÜBBÜK, H. \& PEKMEZCI, M. In vitro propagation of some new banana types (Musa spp.). Turkish Journal of Agriculture and Forestry, Ankara, v. 28, p. 355-361, 2004.

HANBA, Y. T.; KOGAMI, H.; TERASHIMA, L. The effects of growth irradiance on leaf anatomy and photosynthesis in Acer species differing in light demand. Plant Cell and Enviroment, Oxford, v. 25, n. 8, p. 1021-1030, 2002.
JOHANSEN, B.A. Plant microtechnique. New York, McGrawHill, 1940. 523p.

JORGE, M.A.B.; ROBERTSON, A.I.; MASHINGAIDZE, A.B.; $\mathrm{KEOGH}, \mathrm{E}$. How in vitro light affects growth and survival of $e x$ vitro cassava. Annals of Applied Biology, Warwick, v.137, n.3, p.311-319, 2000.

KODYM, A.; ZAPATA-ARIAS, F. J. Natural light as an alternative light source for the in vitro culture of banana (Musa acuminata cv. 'Grande Naine'). Plant Cell, Tissue and Organ Culture, Amsterdam, v. 55, n. 2, p. 141-145, 1999.

KODYM, A.; ZAPATA-ARIAS, F. J. Low-cost alternatives for the micropropagation of banana. Plant Cell, Tissue and Organ Culture, Amsterdam, v. 66, p. 67-71, 2001.

KÖPPEN, W. Climatología: con un estudio de los climas de la tierra. Mexico: Fondo de Cultura Economica, 1948. 478p.

KOZAI, T.; KUBOTA, C.; BYOUNG, R.J. Environmental control for the large-scale production of plants through in vitro techniques. Plant Cell, Tissue and Organ Culture, Amsterdam, v. 51, p. 49-56, 1997.

KRAUS, J.E.; ARDUIM, M. Manual básico de métodos em morfologia vegetal. Rio de Janeiro: EDUR, 1997. 198p.

LABOURIAU, L.G.; OLIVEIRA, J.G.; SALGADOLABOURIAU, M.L. Transpiração de Schizolobium parahyba (Vell) Toledo I. Comportamento na estação chuvosa, nas condições de Caeté, Minas Gerais. Anais da Academia Brasileira de Ciência, v. 33, n. 2, p. 237-257, 1961.

LAMBERS, H.; POORTER, H. Inherent variation in growth rate between higher plants: a search for physiological causes and ecological consequences. Advances in Ecological Research, v.23, p.187-261, 1992.

LIMAJUNIOR, E. deC.;ALVARENGA, A.A. de;CASTRO, E.M. de; VIEIRA, C.V.; OLIVEIRA, H.M. de. Trocas gasosas, características das folhas e crescimento de plantas jovens de Cupania vernalis Camb. submetidas a diferentes níveis de sombreamento, Ciência Rural, Santa Maria, v.35, n.5, p. 1092-1097, 2005.

MARCHAL, J.; SENS, I.; TEISSON, C.Influence des sucres et de facteurs bioclimatiques sur la culture in vitro du bananier. Fruits, Paris, v. 47, n. 1, 1992.

MURASHIGE, T.; SKOOG, F.A. A revised medium for rapid growth and bioassays with tobacco tissue cultures. Physiologia Plantarum, Copenhagen, v.15, p.473-497, 1962.

NAVARRO, C.; TEISSON, C.; CÔTE, F.; GANRY, J. Effects of light intensity and $\mathrm{CO}_{2}$ concentration on growth of banana plants (Musa AAA, cultivar 'Petite Naine') in vitro and subsequent growth following acclimatization. Scientia Horticulturae, Amsterdam, v. 60, p. 41-54, 1994.

ROBINSON, J.C. Bananas and plantains. Wallingford: $C A B$ International. v. 5, p. 48-69, 2003. 238 p.

ROCHA, H.S. Luz e sacarose na micropropagação da bananeira “Prata Anã": alterações morfoanatômicas. 2005.98p. :il. Dissertação (Mestrado em Fitotecnia), Universidade Federal de Lavras, Lavras. 
ROELS, S.; ESCALONA, M.; CEJAS, I.; NOCEDA, C.; RODRIGUEZ, R.; CANAL, M.J.; SANDOVAL, J.; DEBERGH, P. Optimization of plantain (Musa AAB) micropropagation by temporary immersion system. Plant Cell, Tissue and Organ Culture, Amsterdam, v. 82, p. 57-66, 2005.

SANTOS, A.M.; COSTA, F.H.S.; PASQUAL, M.; CASTRO, E.M.; PEREIRA, J.E.S.; MIYATA, L. Efeitos da luz natural e sacarose na perda de água e anatomia foliar de plantas de bananeira, na fase de enraizamento/alongamento in vitro. In: CONGRESSO BRASILEIRO DE FLORICULTURA E PLANTAS ORNAMENTAIS, 16., CONGRESSO BRASILEIRO DE CULTURA DE TECIDOS DE PLANTAS, 3., SIMPÓSIO DE PLANTAS ORNAMENTAIS NATIVAS, 1., 2007, Goiânia, GO. Anais... Goiânia: UFG, 2007. (CD-ROM)

SENDIN, A.P.P.M. Micropropagação de bananeira dos cultivares Maçã e Grande Naine visando a produção de mudas de baixo custo. 2001. 72 p. Dissertação (Mestrado em Genética e Melhoramento de Plantas) - Escola Superior de Agricultura Luiz de Queiroz, Universidade de São Paulo, Piracicaba.

SMITH, W. K.; VOGELMANN, T. C.; DELUCIA, E. H.; BELL, D. T.; SHEPHERD, K. A. Leaf form and photosynthesis. BioScience, v.47, p.785-793, 1997.

STANDAERT-DE-METSANAERE, R.E.A. Economic considerations. In: DEBERGH, P.C.; ZIMMERMAN, R.H. Micropropagation tecnhnology and application. Dordrecht: Kluwer Academic, 1991. p. 131-140.

TALAVERA, C.; CONTRERAS, F.; ESPADAS, F.; FUENTES, G.; SANTAMARÍA, J.M. Cultivating in vitro coconut palms (Cocos nucifera) under glasshouse conditions with natural light, improves in vitro photosynthesis nursery survival and growth. Plant Cell, Tissue and Organ Culture, Amsterdam, v. 83, p. 287-292, 2005.

VUYLSTEKE, D.; DE LANGHE, E. Feasibility of in vitro propagation of bananas and plantains. Tropical Agriculture, Trinidad, v. 62, p. 323-328, 1985. 